\title{
Unifying and diversifying workplace-based efforts for promoting health and preventing disability
}

\author{
Randi W. Aas ${ }^{\mathrm{a}, \mathrm{b}, \mathrm{c}, *}$, Ruth K. Raanaas ${ }^{\mathrm{d}}$ and Lynn Shaw ${ }^{\mathrm{e}}$ \\ ${ }^{\mathrm{a}}$ Oslo and Akershus University College of Applied Sciences, Oslo, Norway \\ ${ }^{\mathrm{b}}$ Presenter, Stavanger, Norway \\ ${ }^{\mathrm{c}}$ University of Stavanger, Norway \\ ${ }^{\mathrm{d}}$ Norwegian University of Life Sciences, Às, Norway \\ ${ }^{\mathrm{e}}$ Pacific Coast University for Workplace Health Science, Port Alberni, British Columbia, Canada
}

\section{Introduction}

In the last decades, the workplace has gradually been more acknowledged as a core arena for interventions aiming at promoting health and preventing disability [1-3].

A first example of this acknowledgement is the frequent use of Workplace or Worksite Health Promotion Programs (WHPP), built on a Public Health tradition, aiming at improving employees' health and lifestyle (i.e., physical activity, healthy eating, weight loss, relaxation, smoking, and drug/alcohol use). The body of knowledge assessing WHPP's effectiveness is increasing [4-6]. A systematic review found more than 300 trials of WHPP published between 2000 and 2012 [5]. Still, the effectiveness of such interventions is for several of the targeted lifestyle changes inconclusive or non-consistent [5-8]. One review even found that high-quality trials tended to report smaller effects than low-quality trials [8].

A second example is Individual Placement Support (IPS), aiming at increasing participation in work, among groups with larger work disability challenges [9]. Inspired by the recovery ideology, the paradigm

\footnotetext{
*Address for correspondence: Randi W. Aas, Presenter, Stavanger Innovation Park, Prof. Olav Hanssens v. 7a, Stavanger 4021, Norway. Tel.: +4791182266; E-mail: randi.aas@ presenter.no.
}

shift in the 80's in psychiatric vocational rehabilitation from "train then place" to "place then train" changed the field, and IPS became the new paradigm $[9,10]$. Competitive employment became the goal, and lengthy pre-employment training was replaced with rapid job search. This made us design "placement interventions" at real workplaces, where the efficient Supported Employment [11, 12] is a great example. To train first and most at workplaces, not in clinics is therefore common today in psychiatric rehabilitation.

A third example is treatment of musculoskeletal disorders (MSD). "Disease prevention" in the mid-1990's suggested to be replaced with "disability prevention", by which workplace foci were strengthened [13-15]. Ten years ago, we were still asking if workplace interventions were an effective means for secondary prevention of low back pain [16]. Today, we know more and judge workplace-based efforts as main solutions for reducing sick leave and return to work for sick-listed employees with MSD and common mental disorders [17-21]. The Workplace Disability Prevention and Integration (WDPI) community of researchers is these days building a strong body of knowledge about workplacebased efforts worldwide, as still much is unknown. For example, we do not know why workplace interventions seem to reduce sick leave and promote return to work, but not affect health outcomes [3, 19]. 
Together with these three examples of changes towards strengthened focus on workplace-based efforts, we also need to mention Disability Management strategies (DM) [22-24]. DM was from the start an employer's commitment to ensure the continued employment and accommodation of employees who experience functional limitations. Employer-based disability management programs grew out of the realization that the solution to occupational disability problems are in the employment setting (i.e. workplaces), and that employers themselves could contribute to reducing disability. Today, DM organizations such as the National Institute for Disability Management and Research (NIDMAR) and Universities such as Pacific Coast University for Workplace Health Science (PCU-WHS) are educating Return to Work coordinators and Disability Managers in over 12 countries [25]. These professionals have today an important role in workplaces efforts to promote health and prevent disability [26].

\section{Unifying fields}

It seems like the effort of building best practice has been a huge challenge in these entire fields. Workplaces are housing complex organizations and environments, which also imply complex human interactions in physical, social, and attitudinal environments [27]. To answer questions as "who", "where", "when", and "how" seems to be difficult. So, even though it seems like WHPP, IPS, WDPI, and DM are different fields, with different target groups, terminology, meeting points, actors, programs, and agendas, we might ask is if these fields and traditions could or should interact more to build a common research and innovation agenda for the future?

Some might argue that they already are moving in the same direction, and a few examples will be mentioned here: From using IPS only towards those with severe mental diseases [12] and head injuries [28], IPS is now applied for groups with different disorders, even MSD [29]. From solely reducing Low Back Pain (LBP), an outspoken message today in the WDPI-field is that most components of interventions need to be developed regardless of what type of disorders the employee have [30]. The WHPP tradition is increasingly measuring outcomes about the consequences on disability (e.g. sick leave and return to work), not only the individuals' habitual or health outcomes. This effort is in line with earlier developments in the IPS and WDPI fields. In the fields of IPS and DM, the use of sheltered workplaces versus real workplaces for training work abilities has commonly being discussed. This might also be an important issue for WDPI. In addition, all fields are today facing the unsolved gap between science and practices providing workplace-based interventions, known as Knowledge Translation [31] and Implementation Science [5]. Different fields might therefore seem to be unified and melted into a need for one common research and innovation agenda for the future.

\section{Diversifying workplace-based efforts}

Simultaneously, as arguing for unification, we will point at the need for diversification of workplace-based efforts. Even though we today know some about health promotion and disability prevention at workplaces, there are still many dimensions unknown and unexplored. And the interventions vary to a large extent, and are vague in the explanations of their effectiveness. We will give some examples here, from this special issue of Work.

First, in all these fields; WHPP, IPS, WDPI, DM, we need to know more about the huge impact supervisors have on health and participation of employees [32, 33]. Skarpaas and colleagues explored supervisors' experiences of challenges involved in the integration of people with mental health problems in an ordinary job placement program. Challenges were motivational; supervisor previous experience, having a realist picture of the situation and knowledge of relevant mental health issues, or structural; collaboration and support both with the trainee itself and with the health and social services. The study also revealed the dilemma when the supervisors knowledge of the trainee's mental health problems on the one hand facilitating support and flexibility, but on the other hand counteracts privacy and equality. Haveraaen and colleagues found that experiencing high supervisor support were associated with being in work three months after rehabilitation. The study highlighted the importance of focusing on workplace efforts and not only client factors in work rehabilitation. Also, Ihlebak and colleagues examined factors that were associated with perceived strain among farmers, offering vocational programmes on their farms. They found that supervisor support was a key issue for promoting health.

Second, these fields might need to know more about the impact of workplace cultural and organizational aspects on health promotion and disability prevention. Several of the studies presented in the special issue examine the relationship between psychosocial or orga- 
nizational structural factors. Dalskau and colleagues' study stresses the significance of the workplace offering structure and flexibility, besides providing the social support factors as understanding, acknowledgement, guidance, and positive feedback. Further, Haveraaen and colleagues found that "low strain jobs" [34] and experience of social support at the workplace were of significance for how fast the sick-listed employee return to work after occupational rehabilitation. Skarpaas and colleagues study highlighted the significance of collaboration among the core providers; workplace, health care, and social insurance office, as a prerequisite to participate in meaningful occupation. However, they stress; it is important to have flexible and supporting environments. How this might be designed more in detailed for different groups, in different phases is still not clear.

Third, based on increasing research that nature elements having aesthetic and fascinating qualities [35], these fields might all need to know more on if and how nature inside and outside workplaces can be taken into account and been used more actively. As part of a trend to offer exercise programs during regular working hours, a study by Calogiuri and colleagues examined the impact of a green exercise intervention on indicators of stress among employees in a municipal workplace. They compared otherwise similar indoor in a gym hall and outdoor physical activity in green surroundings and found more positive scores on self-reported affect and lower levels of blood pressure and cortisol related to exercising outdoors. In the study by Bjørnstad and colleagues, they examined the relationship between nature contact at the workplace and self-reported measures of stress, health and sickness absence among employees, and found that elements of nature inside such as interior plants and window view was related to better health outcomes. The authors conclude that the benefits of nature contact at work can partly be explained by nature contact's potential to reduce stress among people and partly by the perception of being taken care of by the employers. In the study by Raanaas and colleagues the significance for recovery of environmental factors such as view of nature through windows and interior plants were examined among residents in a rehabilitation center. The study concludes that nature elements seem to enhance opportunities for reflection, feeling of meaningfulness and sense of being taken care of which may strengthen their feeling of well-being and resilience. This finding might also be generalized and studied further on the relevance to employees. Interestingly, nature-based interventions at workplaces may thus also fruitfully be studies within the context of more general cultural and organizational aspects at work.

Fourth, these fields might also need to widen how other types of real workplaces, as for example farms, might be used instead of hospital and clinic facilities, or even sheltered workplaces, for outpatient or inpatient occupational rehabilitation. The special issue presents a personal narrative by Westre and Ulveseth describing the experience of the participation at the care farm in a transition to ordinary paid work. In addition, the study by Dalskau and colleagues describe the clients own experiences with care farming. The results focus for example on the presence of nature and animals and the opportunity to reflect on personal functioning. In the descriptive review by Pedersen and colleagues prevocational rehabilitation programs on farms for people with mental health problems are described. The article elaborates on such as the nature environmental factors, and participation in meaningful occupation at a real workplace. To examine how key components outlined by the Norwegian national guidelines for green work are included in care farms in Norway, a case report study is presented by Pedersen and colleagues. It revealed that the components in such farming environments were for example a variety of work activities, adaptation of work tasks, the farmers' support and supervision, experiencing nature, and enhanced structure in everyday life. Ihlebaek and colleagues examined factors related to perceived strain among farmers offering health promotion and disability prevention on their farms. A relevant social or health care worker education by the farmer, as well as good collaboration with the health and social services, and opportunities for supervision by these, were highlighted as important for the care farming to be perceived as a less strenuous task to the farmers.

\section{Innovating the future through establishing a common research agenda}

The workplace is where adults spend the majority of their time. Both health promotion, and disability prevention, integration and management efforts at workplaces can secure that more adults participate in working life. Environmental factors are prerequisites for the enhancing the ability of people to participate in a healthy way that builds work capital of workers at the workplace. By applying a participation perspective as described in ICF [27] we might take actions towards a common research agenda for the future, where new knowledge are integrated [24], and used more cumulatively for a common stronger research front. 
These shifts towards stronger workplace foci have also had impact on social and welfare policy and legislation in the industrial world. One example is the Norwegian Inclusive Working Life Agreement, negotiated between employer's organization, the trade union and the government, and signed in 2001, 2005, 2010, and 2014 [36]. The agreement has three goals: to reduce sick leave, to promote inclusion of disabled, and to enable elderly workers to stay longer in work. All three goals call for a strong workplace offensive. Workplacebased practices have begun to change in accordance, but the actualities of change are a slower process.

Occupational rehabilitation is still in many places mostly focused on changing the individual, not their workplace environments [37]. In line, the traditional gap between interventions towards those with and without an employer might also be less dominant for the future, and supplemented with different types of workplaces, used as arenas for health promotion and disability prevention.

Why and how workplaces seem to have such impact on employees' habits, health, and participation possibilities is also one question for a common future research agenda. However, when different fields seek to be more unified, it seems like we need to diversify workplacebased efforts and interventions. This will enhance the international and cross organizational research efforts to find new solutions on how workplace aspects can benefit from targeted and outcome focused health promotion and disability prevention programs in the future. If, and to what extend these fields; WHPP, IPS, WDPI, and DM are interacting, sharing, and cumulating knowledge is not known. To be able to grasp all types of insight into a highly complex and diverse phenomenon as workplacebased efforts are, unifying the research agenda might be important for our future innovation strength.

\section{References}

[1] Elders LAM, Burdorf A. Workplace interventions. Occupational Environmental Medicine 2004;61:287-8.

[2] van Oostrom SH, Driessen MT, de Vet HCW, Franche RL, Shonstein E, Loisel P, et al. Workplace interventions for preventing work disability. Cochrane Database of Systematic Reviews 2009;(2).

[3] Aas RW. Workplace-based sick leave prevention and return to work. Exploratory studies. Ph.D. Thesis. Stockholm: Karolinska Institutet; 2011.

[4] Engbers LH, van Poppel MN, Chin APMJ, van Mechelen W. Worksite health promotion programs with environmental changes: A systematic review. American Journal of Preventive Medicine 2005;29(1):61-70.
[5] Wierenga D, Engbers LH, Van Empelen P, Duijts S, Hildebrandt VH, Van Mechelen W. What is actually measured in process evaluations for worksite health promotion programs: A systematic review. Bmc Public Health 2013;13.

[6] Aas RW, Tuntland H, Holte K, Roe C, Lund T, Marklund S, Moller A. Workplace interventions for neck pain in workers. Cochrane Database of Systematic Reviews 2011;4.

[7] Jepson RG, Harris FM, Platt S, Tannahill C. The effectiveness of interventions to change six health behaviours: A review of reviews. BMC Public Health 2010;10:538.

[8] Rongen A, Robroek SJ, van Lenthe FJ, Burdorf A. Workplace health promotion: A meta-analysis of effectiveness. American Journal of Preventive Medicine 2013;44(4):406-15.

[9] Drake RE. A brief history of the Individual Placement and Support model. Psychiatric Rehabilitation Journal 1998;22(1).

[10] Bond GR. Principles of the individual placement and support model: Empirical support. Psychiatric Rehabilitation Journal Summer 1998;22(1):11-13 1998;22(1):3.

[11] Handler J, Doel K, Henry A, Lucca A. Implementing supported employment services in a real-world setting. Psychiatric Services 2003;54(7):960-2.

[12] Bond GR. Supported employment: Evidence for an evidencebased practice. Psychiatric Rehabilitation Journal 2004;27(4): 345-59.

[13] Loisel P, Durand P, Diallo B, Vachon B, Charpentier N, Labellle J. From evidence to community practice in work rehabilitation: The Quebec experience. The Clinical Journal of Pain 2003;19:105-13.

[14] Loisel P, Durand MJ, Berthelette D, Vezina N, Baril R, Gagnon D. Disability prevention-New paradigm of the management of occupational back pain. Disease Management \& Health Outcomes 2001;9(7):351-60.

[15] Frank JW, Brooker AS, DeMaio SE, Kerr MS, Maetzel A, Shannon HS, Sullivan TJ, Norman RW, Wells RP. Disability resulting from occupational low back pain. Part II: What do we know about secondary prevention? A review of the scientific evidence on prevention after disability begins. Spine 1996;21(24):2918-29.

[16] Elders LAM, Burdorf A. Workplace interventions. Occupational Environmental Medicine 2004;61:287-8.

[17] Anema JR, Cuelenaere B, van der Beek AJ, Knol DL, de Vet HC, Van Mechelen W. The effectiveness of ergonomic interventions on return-to-work after low back pain; a prospective two year cohort study in six countries on low back pain patients sicklisted for 3-4 months. Occupational \& Environmental Medicine 2004;61(4):289-94.

[18] Anema JR, Steenstra IA, Bongers PM, de Vet HC, Knol DL, Loisel P, van Mechelen W. Multidisiplinary rehabilitation for subacute low back pain: Graded activity or workplace intervention or both? A randomized controlled trial. Spine 2007;32(3):291-8.

[19] van Oostrom SH, Driessen MT, de Vet HC, Franche RL, Schonstein E, Loisel P, van Mechelen W, Anema JR. Workplace interventions for preventing work disability. The Cochrane Database of Systematic Reviews 2009;(2):CD006955.

[20] Lambeek LC, Bosmans JE, Van Royen BJ, Van Tulder MW, Van Mechelen W, Anema JR. Effect of integrated care for sick listed patients with chronic low back pain: Economic evaluation alongside a randomised controlled trial. BMJ (Clinical Research Ed) 2010;341:c6414-c6414.

[21] Bultmann U, Sherson D, Olsen J, Hansen CL, Lund T, Kilsgaard J. Coordinated and tailored work rehabilitation: A randomized controlled trial with economic evaluation undertaken with workers on sick leave due to musculoskele- 
tal disorders. Journal of Occupational Rehabilitation 2009; 19(1):81-93.

[22] Chan F, Taylor D, Currier K, Chan CCH, Wood C, Lie A, Lui J. Disability management practitioners: A work behavior analysis. Journal of Vocational Rehabilitation 2000;15:47-56.

[23] Currier KF, Chan F, Berven NL, Habeck RV, Taylor DW. Functions and knowledge domains for disability management practice. Rehabilitation Counseling Bulletin 2001;44(3): 133-43.

[24] Olsheski JA, Rosenthal DA, Hamilton M. Disability management and psychosocial rehabilitation: Considerations for integration. Work 2002;19(1):63-70.

[25] Shaw W, Hong Q-N, Pransky G, Loisel P. A Literature Review Describing the Role of Return-to-Work Coordinators in Trial Programs and Interventions Designed to Prevent Workplace Disability. Journal of Occupational Rehabilitation 2008;18(1):2-15.

[26] Gardner BT, Pransky G, Shaw WS, Nha Hong Q, Loisel P. Researchers perspectives on competencies of return-to-work coordinators. Disability \& Rehabilitation 2010;32(1):72-8.

[27] WHO: International classification of functioning, disability and health, ICF. Geneva: World Health Organization 2001.

[28] Shames J, Treger I, Ring H, Giaquinto S. Return to work following traumatic brain injury: Trends and challenges. Disability and Rehabilitation 2007;29(17):1387-95.

[29] Li-Tsang CW, Li EJ, Lam CS, Hui KY, Chan CC. The effect of a job placement and support program for workers with musculoskeletal injuries: A randomized control trial (RCT) study. Journal of Occupational Rehabilitation 2008;18(3): 299-306.

[30] Loisel P, Anema JR. (eds.) Handbook of work disability. London: Springer; 2013.

[31] Straus SE, Tetroe J, Graham ID. Defining knowledge translation. Canadian Medical Association Journal 2009;181(34):165-8.

[32] Aas RW, Ellingsen K, Lindoe P, Möller A. Leadership qualities in the return to work process: A content analysis. Journal of Occupational Rehabilitation 2008;18(4):335-46.

[33] Nyberg A, Bernin P, Theorell T. The impact of leadership on the health of subordinates. In.: SALTSA; Working life research in Europe; 2005.

[34] Karasek R, Theorell T. Healthy work. Stress, productivity, and the reconstruction of working life. USA: Basic Books, A division of Harper Collins Publishers; 1990.

[35] Brewer S, Van Eerd D, Amick BC, 3rd, Irvin E, Daum KM, Gerr F, Moore JS, Cullen K, Rempel D: Workplace interventions to prevent musculoskeletal and visual symptoms and disorders among computer users: A systematic review. Journal of Occupational Rehabilitation 2006;16(3):325-58.

[36] Norwegian Government: Letter of Intent regarding a more inclusive working life, 2010-2013 (The IA-Agreement) In.; 2010.

[37] Shaw L. Are we ready to address the new expectations of work and workers in the transforming world of work? Work $2013 ; 44: 8$ 